\title{
Autoridade religiosa, diversidade e o princípio pluralista
}

\author{
Claudio de Oliveira Ribeiro*
}

\section{Resumo}

O texto apresenta resultados de pesquisa sobre a diversidade no campo religioso brasileiro, analisada sob o princípio pluralista, e como ela incide no debate acerca do exercício da autoridade religiosa. Metodologicamente, os olhares a respeito das experiências religiosas priorizaram interpretá-las a partir dos entrelugares e fronteiras das culturas, dos espaços interstícios e não institucionais de poder e das possibilidades de visibilidade e empoderamento dos grupos subalternos. Com isso, foi possível realçar as formas pelas quais o poder é exercido internamente nos distintos contextos religiosos, considerando as diversas contradições e ambiguidades que possuem. Entre os resultados da pesquisa, estão descrições sobre o quadro do pluralismo religioso brasileiro, com destaque para a visão diversificada sobre autoridade religiosa, levando em conta o contexto plural da sociedade e a diversidade interna das expressões religiosas. Nesse quadro se destacam variados processos de reconfiguração do quadro religioso brasileiro, como o deslocamento do religioso para esferas culturais, o primado das experiências sensoriais no campo religioso, as variações que a diversidade sexual e de gênero trazem para o campo de cada expressão religiosa e as formas de fundamentalismos, ecumenismos, trânsitos e múltiplas participações religiosas. A pesquisa abordou também as fontes que conferem legitimidade à autoridade religiosa, possibilitando o exercício da liderança e da representação: (i) o conhecimento formal ou informal do texto sagrado (no caso das religiões que o possuem); (ii) as formas de sapiência acumuladas no conjunto das experiências de vida; (iii) o carisma que determinadas pessoas ou grupos cultivam e que reforça a capacidade de articulação e mobilização coletiva ou na gerência da vida comunitária ou institucional; e (iv) o status socioeconômico e cultural conferido pelas próprias comunidades ou instituições religiosas ou ainda por setores externos a elas. Palavras-chave: autoridade; religião; princípio pluralista; carisma; diversidade.

* Universidade Federal de Juiz de Fora. Doutor em Teologia pela Pontifícia Universidade Católica-RJ. E-mail: cdeoliveiraribeiro@gmail.com . 


\title{
Religious authority, diversity and the pluralist principle
}

\begin{abstract}
The text presents research results on diversity in the Brazilian religious field, analyzed under the pluralist principle, and how it influences the debate on the exercise of religious authority. Methodologically, the views on religious experiences prioritized interpreting them from the in-between places and borders of cultures, from the interstices and noninstitutional spaces of power and from the possibilities of visibility and empowerment of subordinate groups. With this, it was possible to highlight the ways in which power is exercised internally in different religious contexts, considering the various contradictions and ambiguities they have. Among the research results, there are descriptions about the framework of Brazilian religious pluralism, highlighting the diversified view of religious authority, considering the plural context of society and the internal diversity of religious expressions. In this framework, various processes of reconfiguration of the Brazilian religious framework stand out, such as the shift from religious to cultural spheres, the primacy of sensory experiences in the religious field, the variations that sexual and gender diversity bring to the field of each religious expression and forms of fundamentalisms, ecumenisms, transits and multiple religious participations. The research also addressed the sources that give legitimacy to religious authority, enabling the exercise of leadership and representation: (i) formal or informal knowledge of the sacred text (in the case of religions that have it); (ii) the forms of wisdom accumulated in the set of life experiences; (iii) the charisma that certain people or groups cultivate and which reinforces the capacity for articulation and collective mobilization or in the management of community or institutional life; and (iv) the socioeconomic and cultural status conferred by the communities or religious institutions themselves or even by sectors outside them.
\end{abstract}

Keywords: authority; religion; pluralist principle; charisma; diversity.

\section{Autoridad religiosa, diversidad y el principio pluralista}

\section{Resumen}

El texto presenta resultados de investigación sobre la diversidad en el campo religioso brasileño, analizados bajo el principio pluralista, y cómo influye en el debate sobre el ejercicio de la autoridad religiosa. Metodológicamente, las visiones sobre las experiencias religiosas priorizaron interpretarlas desde los espacios intermedios y fronteras de las culturas, desde los intersticios y espacios de poder no institucionales y desde las posibilidades de visibilidad y empoderamiento de los grupos subordinados. Con esto, fue posible resaltar las formas en que el poder se ejerce internamente en diferentes contextos religiosos, considerando las diversas contradicciones y ambigüedades que tienen. Entre los resultados de la investigación, se encuentran descripciones sobre el marco del pluralismo religioso brasileño, destacando la visión diversificada de la autoridad religiosa, considerando el contexto plural de la sociedad y la diversidad interna de las expresiones religiosas. En este marco, se destacan diversos procesos de reconfiguración del marco religioso brasileño, como el paso de la esfera religiosa a la cultural, la primacía de las experiencias sensoriales en el campo religioso, las variaciones que la diversidad sexual 
y de género traen al campo de cada religioso. expresión y formas de fundamentalismos, ecumenismos, tránsitos y participaciones religiosas múltiples. La investigación también abordó las fuentes que dan legitimidad a la autoridad religiosa, posibilitando el ejercicio del liderazgo y la representación: (i) conocimiento formal o informal del texto sagrado (en el caso de religiones que lo posean); (ii) las formas de sabiduría acumuladas en el conjunto de experiencias de vida; (iii) el carisma que cultivan determinadas personas o grupos y que refuerza la capacidad de articulación y movilización colectiva o en la gestión de la vida comunitaria o institucional; y (iv) el estatus socioeconómico y cultural conferido por las propias comunidades o instituciones religiosas o incluso por sectores ajenos a ellas.

Palabras-clave: autoridad; religión; principio pluralista; carisma; diversidad.

\section{Introdução}

A análise que ora apresentamos é resultado de um trabalho de assessoria a um grupo de pesquisa na área de religião e comunicação preocupado em oferecer elementos sobre o pluralismo religioso aos profissionais desse campo.

O ponto central são os aspectos em torno da noção de autoridade religiosa, especialmente como ela pode ser vista no contexto plural em que as sociedades vivem na atualidade. Serão destacadas as formas pelas quais o poder é exercido internamente nos distintos contextos religiosos, a diversificação das compreensões relativas ao exercício e à natureza da autoridade religiosa na medida em que estas podem ser vistas pelos setores externos por variados ângulos e a heterogeneidade das expressões religiosas, tanto em níveis mundiais, nacionais ou regionais quanto no âmbito comunitário ou local.

Para isso, metodologicamente, constituímos quatro blocos de análises. O primeiro apresenta uma síntese das principais bases conceituais do princípio pluralista, que orienta o conjunto das reflexões.

O segundo bloco versa sobre o quadro do pluralismo religioso brasileiro, visto a partir desse princípio. Entre os pontos a serem realçados, estão o fato de como a visão sobre autoridade religiosa se diversifica no contexto plural da atualidade, aspectos da diversidade e da complexidade das experiências e expressões religiosas, as análises acerca do deslocamento do religioso para esferas culturais, o primado das experiências sensoriais no campo religioso e as formas de fundamentalismos, ecumenismos, trânsitos e múltiplas participações religiosas.

O terceiro bloco trata mais especificamente da temática da autoridade religiosa e das fontes que conferem legitimidade a ela e das formas 
pelas quais engendra dinâmicas de mobilização nos campos comunitário, institucional e social.

Entre os vários elementos que conferem autoridade às pessoas que pertencem a grupos religiosos e que com ela exercem liderança e representação, a pesquisa destaca quatro: o conhecimento formal ou informal do texto sagrado (no caso das religiões que o possuem); as formas de sapiência e de conhecimento prático acumuladas nas experiências de vida; o carisma que determinadas pessoas ou grupos cultivam e que reforça a capacidade de articulação e mobilização coletiva ou na gerência da vida comunitária ou institucional; e o status socioeconômico e cultural conferido pelas próprias comunidades ou instituições religiosas ou por setores externos a elas.

O quarto bloco trata da relação entre o papel das mídias e o exercício da autoridade religiosa, considerando especialmente o fato de as mídias terem se constituído palco e veículo de mudanças significativas para as religiões no início do século 21. Elas passaram de coadjuvantes a protagonistas de processos religiosos, com variadas implicações para as questões relativas à autoridade.

\section{O princípio pluralista}

As reflexões sobre o princípio pluralista têm sido efetuadas a partir do enfrentamento de pelo menos três desafios interligados entre si que emergem dos estudos de religião no Brasil e da situação teológica latino-americana: i) melhor compreensão da complexidade da realidade socioeconômica e cultural; ii) equacionamento mais adequado das relações entre racionalidade e subjetividade; e iii) os encontros e desencontros da teologia com a pluralidade, seja metodológica, seja religiosa, seja antropológica.

A teologia latino-americana em décadas anteriores, por exemplo, priorizou a dimensão política para suas interpretações e nem sempre prestou a devida atenção às diferenças culturais, fortemente híbridas e entrecruzadas com a diversidade das expressões religiosas. Ela também não esteve suficientemente atenta às demandas da vida que surgem na realidade do cotidiano e às dimensões fundamentais da vida humana, como a corporeidade, a sexualidade, o prazer, o lúdico e a festividade. Em outros campos dos estudos de religião, tais limitações também estão presentes.

A noção do princípio pluralista tem se tornado útil como instrumento de análise da diversidade religiosa. Ele procura olhar a realidade a partir dos entrelugares das culturas, das zonas fronteiriças que cada grupo religioso possui com outras expressões religiosas, com as diferentes culturas ou com 
aquelas forjadas com as próprias divisões políticas e ideológicas internas de cada grupo. Com isso, o princípio pluralista facilita a visibilidade e o empoderamento de grupos subalternos e contribui para maior explicitação das diversidades (RIBEIRO, 2020).

O princípio pluralista, formulado com base em lógicas plurais, ecumênicas e de alteridade, possibilita melhor compreensão da diversidade do quadro religioso e também das ações humanas. Não se trata apenas de uma indicação ética ou "catequética"; com ele, as avaliações tornam-se mais consistentes, uma vez que possibilitam melhor identificação do "outro", não idealizado, mas concretamente identificado, especialmente as pessoas e grupos que são invisibilizados dentro da visão sociológica que Boaventura de Souza Santos (2010) chamou de "sociologia das ausências". A sensibilidade com as distintas expressões culturais ou religiosas, majoritárias ou minoritárias, fronteiriças ou não, favorece uma "sociologia das emergências" de novos rostos, variados perfis religiosos, multiplicidades de olhares, perspectivas e formas plurais de atuação.

Com essa perspectiva "policromática", o princípio pluralista se constitui em um instrumento analítico, hermenêutico e propositivo, composto por processos de mediações. Estas se orientam para: (i) a análise da realidade sociocultural e religiosa; (ii) a interpretação dela a partir de visões pluralistas e de alteridade ecumênica; e (iii) a indicação de elementos práticos que possam, a partir de perspectivas críticas, autocríticas e de diálogo, dar visibilidade e reforçar o poder de experiências de grupos subalternos que são geradas nas bordas e fronteiras das culturas e das esferas de institucionalidades.

Nas bases conceituais do princípio pluralista está a compreensão de entrelugar, como trabalho fronteiriço da cultura, conforme nos indica Homi Bhabha (2001), que requer um encontro com "o novo" que não seja mera reprodução ou continuidade de passado e presente. Para as nossas reflexões, especialmente no que comumente nos referimos à necessidade de alargamento de horizontes metodológicos para o estudo da religião, consideramos que o "local da cultura" é fundamental no processo que advogamos de estabelecer mediações socioanalíticas para as interpretações teológicas e, também, para as análises científicas da religião em geral. O conceito de entrelugar está relacionado à visão e ao modo como grupos subalternos se posicionam ante o poder e como realizam estratégias de empoderamento. Tais posicionamentos geram entrelugares, especialmente experimentados nas malhas do cotidiano, em que aparecem com maior nitidez questões de âmbito comunitário, social e político. A posição de fronteira permite maior visibilidade das estruturas 
de poder e de saber, o que pode ajudar na apreensão das subjetividades de povos subalternos.

Com as visões acerca da noção de entrelugares e de fronteiras, constituídas com base nas concepções de Homi Bhabha e Boaventura de Souza Santos, reforçamos a perspectiva dos estudos culturais que em solo latino-americano ganhou um novo conteúdo crítico. Trata-se da perspectiva ou giro decolonial. Essas expressões, que se distinguem do 'pós-colonial' ou do 'descolonial', possuem um sentido estratégico que revela interpelações políticas e epistemológicas de reconstrução de culturas, instituições e relações sociais. Tais interpelações críticas são marcadas por certo caráter propositivo e prático e por ações concretas no âmbito cultural e político. O 'decolonial' indica uma desobediência epistemológica sem a qual "não será possível o desencadeamento epistêmico e, portanto, permaneceremos no domínio da oposição interna aos conceitos modernos e eurocentrados, enraizados nas categorias de conceitos gregos e latinos e nas experiências e subjetividades formadas dessas bases" (MIGNOLO, 2008, p. 288).

A tarefa decolonial consiste em construir a vida a partir de outras categorias de pensamento que estão para além dos pensamentos ocidentais dominadores. Trata-se de uma postura e atitudes permanentes de transgressão e de intervenção no campo político e cultural, na incidência das culturas subalternalizadas e invisibilizadas, nas quais se pode identificar, visibilizar e incentivar lugares de exterioridade e de construções críticas alternativas e plurais.

O princípio pluralista, em sua capacidade de mediação prática das análises científicas e hermenêuticas da realidade sociorreligiosa, identifica algumas tarefas decoloniais, que entre elas estão: (i) a crítica à visão de um pensamento único; (ii) a revisão da perspectiva de "centrocentrismos"; (iii) o questionamento da visão de universalismo das ciências e da ética; (iv) a análise crítica da supremacia da racionalidade formal técnico-científica moderna e uma avaliação criteriosa da forma meramente conceitual da produção do conhecimento; (v) a revisão da noção de indivíduo desprovida da interação constituinte do humano com a comunidade, a história, a natureza e o cosmo; e (vi) o exame da ideologia das identidades rígidas e fixas (RIBEIRO, 2020b).

Com isso, as aproximações religiosas e a valorização do pluralismo podem ser não somente percebidas e terem suas tendências identificadas nas análises, mas ser sobretudo construídas. Essa tarefa pertence aos próprios grupos religiosos e da interação deles na sociedade, mas os estudos de religião 
podem cooperar oferecendo análises cujas bases sejam sólidas e ao mesmo tempo criativas e indicadoras de novos caminhos.

Nossa intenção em articular o princípio pluralista com análises sobre a diversidade - metodológica, religiosa e antropológica, e nesta reflexão especificamente sobre autoridade religiosa - se fundamenta, entre outros aspectos, na necessidade de se responder às demandas em torno da decolonialidade (RIBEIRO, 2020b).

\section{O contexto de pluralismo religioso}

Os variados temas relativos às religiões e às formas similares de espiritualidades, tanto no contexto brasileiro quanto no mundial, não podem ser abordados sem se levar em conta a realidade de pluralismo que marca as sociedades hoje. As reflexões em torno do tema da autoridade religiosa não fogem a essa regra e cuidado. Há uma considerável diversidade de práticas e compreensões do que seja uma autoridade religiosa, e tal pluralidade envolve as diferentes instituições e movimentos religiosos.

Em geral, essas múltiplas compreensões estão intimamente articuladas com as formas pelas quais o poder é exercido internamente, tanto em nível macro (que pode abarcar, por exemplo, uma religião com inserção mundial) quanto em níveis do cotidiano e das relações internas de uma pequena comunidade religiosa. A compreensão relativa às autoridades religiosas também se diversifica na medida em que estas podem ser vistas pelos setores externos por diferentes ângulos.

\subsection{Autoridade religiosa no contexto plural}

A concepção e a forma do exercício da autoridade em uma comunidade ou instituição religiosa podem variar dependendo de certos fatores. Em geral, os grupos externos a determinada comunidade religiosa (as mídias, outros grupos religiosos, os poderes públicos etc.) olham-na sob perspectivas mais formais e institucionalizadas. Nem sempre estão atentos aos movimentos internos de maior ou menor legitimação das autoridades, à heterogeneidade dos grupos e das confissões religiosas, tanto em níveis mais gerais (mundiais, nacionais ou regionais) quanto no âmbito de uma comunidade ou grupo local (CAMURÇA, 2013).

Historicamente, ainda que haja uma variação de religião para religião, tanto os fatores internos que configuram as relações de poder quanto as visões externas tendem a concentrar o foco de autoridade em homens brancos 
e de poder econômico e escolaridade mais elevados. No entanto, em quase todos os ramos religiosos há movimentos e situações que contradizem essa constatação; isso desafia especialmente os setores externos - incluindo as mídias e variados campos da sociedade civil - a perceberem as ambiguidades e pluralidades internas de cada grupo e a criarem canais de visibilidade e expressão para eles.

No Brasil, é considerável, por exemplo, o papel de mulheres no campo cristão-evangélico, com a presença de pastoras e bispas (SOUZA, 2010), e também no universo afro-brasileiro, com as mães de santo (CARNEIRO, 2020). Além disso, é possível destacar o exercício da autoridade religiosa de pessoas com escolaridade básica, pouco letradas e pobres, especialmente no campo pentecostal, com pastores que atuam em áreas periféricas, e pais de santo, no campo das religiões afro-brasileiras. Esses grupos praticamente ficam ausentes dos espaços das mídias convencionais.

Essas mídias, quase sempre desprovidas do princípio pluralista, costumam olhar a realidade religiosa sob um prisma de homogeneidade, formalidade e institucionalidade hegemônica, não valorizando as diversidades internas de cada religião e as do quadro religioso em geral nem dando voz aos grupos dissidentes, alternativos e contra-hegemônicos (CUNHA, 2020).

\subsection{A diversidade do quadro religioso brasileiro}

Sob a luz do princípio pluralista, a diversidade religiosa brasileira pode ser mais bem compreendida em suas nuances, fronteirizações e movimentos internos. De fato, a vivência religiosa no Brasil, assim como em outras partes do globo, sofreu fortes mudanças nas últimas décadas.

Alguns aspectos do novo perfil devem-se, sobretudo: (i) à afirmação religiosa indígena e afro-brasileira, em suas diversas matrizes, especialmente as formas de Umbandas, Candomblés e Encantarias, e uma série de expressões culturais regionais, em sua maioria híbridas e recompostas; (ii) à multiplicação e maior visibilidade dos grupos orientais, em toda a sua diversidade étnica e cultural, tanto as diferentes expressões de Budismo, de Xintoísmo e de Confucionismo como as religiões recém-chegadas ao Brasil tais como Seichono-Ie, Perfect Liberty e a Igreja Messiânica, e outras como Fé Bahaí, Hare Krishna e Osho; (iii) à presença pública, embora minoritária, das diferentes expressões do Judaísmo e do Islã; (iv) à força popular do Espiritismo Kardecista e às expressões espiritualistas e mágicas que se configuram em torno da chamada Nova Era, e outras formas em ascensão como Wicca e 
Rosa Cruz; (v) a expressões religiosas caracterizadas pelo ritual de consumo de ayahuasca, como o Santo-Daime, Barquinha e União Vegetal; (vi) ao esforço nucleador dos Mórmons e Testemunhas de Jeová; (vii) ao fortalecimento institucional dos movimentos católicos de renovação carismática, que reforçam a pluralidade católica constituída por dezenas de ordens, grupos e tendências doutrinárias e teológicas; (viii) ao crescimento evangélico, em especial o das igrejas e movimentos pentecostais, ao lado da visibilidade pública e midiática desses grupos, somada à presença e atividade das igrejas evangélicas chamadas 'tradicionais'; e (ix) à maior atenção à intensificação das experiências de trânsito religioso e de múltiplas participações (ou pertenças) religiosas.

Todas essas expressões, além de outras, formam um cenário complexo e de matizes as mais diferenciadas, ainda mais se forem somadas as formas religiosas seculares e culturais, como as terapêuticas, de autoajuda, econômicas, midiáticas e de entretenimento. Não se pode esquecer o número crescente de pessoas que se declaram sem religião, que no Brasil somente não está acima dos grupos católicos e evangélicos (RIBEIRO, 2020). A pluralidade desse quadro implica direta e proporcionalmente a diversidade de formas de exercício do poder e da autoridade religiosa.

Isso tem levado ao fato de os temas relativos ao pluralismo religioso estarem ganhando destaque no debate acadêmico atual. Em parte, tal ênfase se dá como resposta à realidade sociocultural na qual encontramos nas últimas décadas maior visibilidade da diferença religiosa, no Brasil e no mundo, maior intensidade no debate sobre religião e democracia, especialmente os assuntos ligados à laicidade do Estado, mas também a ambiguidade de termos, ao mesmo tempo, situações conflitivas e busca de diálogo entre grupos religiosos distintos em diferentes áreas da vida social.

Para exemplificar a contradição presente em tais situações, podemos citar dois elementos. O primeiro, de caráter negativo, está relacionado aos atos e às culturas de intolerância religiosa no país. O segundo, visto como positivo, são as vivências de transreligiosidade, boa parte delas resultante de aproximações e diálogos.

Quanto ao primeiro, Clarissa de Franco (2020, p. 199) observa:

As religiões de matrizes africanas como Umbanda e Candomblé são, com expressiva diferença dos demais grupos religiosos, as religiões que mais sofrem ataques no Brasil. Há denúncias de violências dirigidas tanto a pessoas religiosas quanto aos terreiros e espaços de culto. Alguns segmentos evangélicos e católicos também relatam sofrer intolerâncias, assim como o grupo de muçulmanos, que vem crescendo nos anos recentes no Brasil. 
Quanto ao segundo exemplo, a transreligiosidade, Gilbraz Aragão (2020, p. 289-290) afirma:

A espiritualidade transreligiosa não se refere a uma religião genérica e superficial, que pudesse pairar no ar dos valores, sem inserção comunitária e sem assumir nenhuma vestimenta cultural. Trata-se de ter um rosto próprio e corpo cultural concreto, mas desenvolvendo místicas que vão além da própria referência teológica de crenças e ritos, rumo a uma dimensão maior e aberta, de experiência espiritual comum entre e além das religiões, incluindo as vivências pós e não-religiosas. A situação de pluralidade provoca debates e confrontos inter-religiosos, buscas de orações e engajamentos comuns, que acabam despertando místicas transreligiosas. $\mathrm{O}$ transreligioso assegura a tradução de uma tradição espiritual para várias outras, decifrando o significado que as une, embora igualmente as ultrapasse.

Ao se olhar mais detidamente para o quadro religioso brasileiro, é possivel verificar que há um crescente número de pessoas que desejam a experiência da fé sem a necessidade de submissão às instituições religiosas ou mesmo sem adesão forte à vivência religiosa comunitária (TEIXEIRA; MENEZES, 2013). Na fé privatizada, cada pessoa escolhe o que deseja crer, onde e como exercer a experiência religiosa, não obstante os instrumentos e mecanismos ideológicos e massificantes que marcam esse cenário. No entanto, tais expressões quase sempre são acompanhadas por dimensões públicas e articuladas com aspectos políticos. "Notemos que o contexto da pluralidade não reduziu a presença das religiões no espaço público. A participação delas, inclusive, ampliou-se para a ocupação de amplos setores de abrangência pública como os veículos midiáticos desde o fim do século 20, principalmente [...]" (FRANCO, 2020, p. 195).

Tais características estão presentes no quadro religioso brasileiro e se reforçam a partir de vários elementos. Um deles são as formas de trânsito religioso. Sandra Duarte de Souza (2020, p. 284) assim analisa:

A prática do trânsito religioso tem relativizado os vínculos e enfraquecido o poder regulador das instituições e dos sistemas religiosos. Ela é a expressão do questionamento das fidelidades institucionais e revela a crise de credibilidade dessas instituições. Crença e pertença já não compõem a mesma equação necessariamente. $\mathrm{O}$ desejo de poder da instituição passa pela adesão inconteste às suas normas, à sua tradição, às suas crenças e práticas, rechaçando, e até mesmo reprimindo, o "flerte" com outros sistemas de sentido, como também nega ao sujeito ordinário a agência no processo de construção simbólica. A 
rigidez dogmática e as determinações formatadoras das instituições religiosas conflitam com a forma fluida de vivenciar a religião na contemporaneidade.

O trânsito religioso se dá não apenas na migração de uma religião para outra, mas também na recomposição simbólico-cultural de diferentes sistemas de crenças. Isso ocorre em diferentes tipos de expressão religiosa: (i) o que afirma determinada pertença e admite experimentar outras expressões religiosas; (ii) o que, por motivos pessoais nem sempre confessáveis, declara uma religião, mas exerce outra; (iii) o que harmoniza e integra relativamente bem mais de uma tradição religiosa; (iv) o que não adere a uma religião específica, mas transita por mais de uma; e (v) aquele que, mesmo mantendo a sua pertença religiosa, articula elementos simbólico-rituais de outras religiões (RIBEIRO; CATENACI, 2017).

Em conexão com essas situações, está a realidade das múltiplas participações religiosas (MPR). Estas representam um "fenômeno muito comum e visto como positivo em contextos asiáticos, por exemplo, mas é visto negativamente e rotulado, não sem equívocos, como 'sincretismo' em contextos coloniais por todo o mundo. Em outras palavras, a MPR não é algo novo, mas vem ganhando destaque pois tem deixado de ser um fenômeno à margem [...]" (TOSTES, 2020, p. 157).

Ao analisar esse quadro, a autora mostra também

a importância de se pensar criticamente o quadro religioso, não a partir do conceito moderno de religião, em geral compartimentalizado, racionalizado e formal, mas a partir de como se dá efetivamente a relação entre vida cotidiana e expressões de fé. Este elemento é de fundamental importância porque as experiências concretas de múltipla participação religiosa em geral articulam expressões religiosas majoritárias, no caso do Brasil o Cristianismo católico, com formas e vivências populares arraigadas na cultura, sobretudo a partir das raízes indígenas e afro-brasileiras. Estas, em geral, possuem compreensões salvíficas de natureza cósmica, ou seja, encontram o sentido divino mais profundo na natureza e nas realidades cotidianas. (TOSTES, 2020, p. 160)

Outro elemento de destaque na diversidade religiosa brasileira é o fato de se terem simultaneamente um agravamento e recrudescimento das práticas fundamentalistas e um florescimento de visões religiosas mais arejadas, abertas ao diálogo e valorizadoras do pluralismo (TEIXEIRA, 2008). 
Não obstante o fortalecimento institucional e popular de propostas religiosas com acentos mais verticalistas, em geral conflitivas, fechadas ao diálogo, marcadas por violência simbólica e de caráter fundamentalista, o campo religioso tem experimentado também formas ecumênicas de diálogo entre grupos religiosos distintos. Pressupomos um tipo de fundamentalismo, mais associado a certa refutação religiosa das perspectivas antropológicas que levam em conta as formas de evolução do universo e da vida humana e as explicações mais racionais da vida, assim como reações contra posturas mais abertas no campo da sexualidade, especialmente no que se refere ao direito das mulheres ao próprio corpo e ao prazer e também à homoafetividade. (RIBEIRO, 2021, p. 44)

Em direção similar, Cris Serra e Vanessa Leite apresentam diversas interlocuções entre diversidade sexual e de gênero e o campo religioso:

A gradual conquista de legitimidade e espaço social pela diversidade sexual e de gênero, como vimos, não é um processo linear. Atravessado por contradições e disputas, vai interpelando diferentes atores sociais e desafiandoos a questionar suas próprias concepções sobre sexualidade e gênero. Aí se incluem as pessoas e comunidades religiosas - inclusive em nível institucional, mas não só. Nesse sentido, as respostas construídas a partir de diálogos, conflitos e tensionamentos - tanto dentro das religiões quanto entre as religiões e seus "outros" - variam ao longo do tempo e correspondem a um amplo espectro de atitudes. Este compreende desde repúdio, condenação e exclusão da diversidade sexual e de gênero, dando continuidade a uma concepção (hegemônica no Ocidente cristão) do sexo e do corpo como fontes de perigo, restringindo a sexualidade legítima à reprodução; e vai até a revisão e retificação de posturas e doutrinas a respeito do tema, passando por diferentes iniciativas e formas de acolhida. (SERRA; LEITE, 2021, p. 223-224)

O quadro religioso brasileiro tem apresentado as características até aqui descritas, além do fato de que tem sido fortemente marcado por elementos de massificação e de reprodução de lógicas individualistas, intimistas, consumistas, de ascensão social e de prosperidade econômica e material no âmbito individual e familiar. Tais marcas estão conectadas com dimensões e projetos de natureza pública, social e política. As práticas de marketing, em geral aliadas aos interesses do sistema econômico, apropriam-se desses discursos religiosos para seus fins, e vice-versa. Assim, muitas pessoas passam a viver a experiência religiosa apenas ou preponderantemente com o recurso do rádio, da TV e da internet (CUNHA, 2020). 
Não obstante a isso, ao mesmo tempo diversas formas religiosas comunitárias se mantêm ou ressurgem com vínculos e compromissos sociais, seja dentro de uma linha de humanização e de transformação social que vise à cidadania, à conquista de direitos, à sustentabilidade ecológica e a demais aspectos da perspectiva de justiça social, seja a partir de elementos de manutenção do status quo. Trata-se de um processo ambíguo e marcado por contradições que interferem diretamente nas formas de exercício da autoridade.

\subsection{A complexidade do quadro das expressões religiosas}

As reflexões feitas até aqui reforçam a ideia de que os processos de secularização vividos em meio à modernidade não produziram, como se esperava, o desaparecimento ou a atenuação das experiências religiosas. Ao contrário, no campo cristão, por exemplo, as formas pentecostais e carismáticas ganharam apego popular, espaço social e base institucional, tanto no mundo evangélico como no católico. Outras religiões também vivenciam, no Brasil e no mundo, momentos de reflorescimento (FRANCO; RIBEIRO, 2020).

Sandra Duarte de Souza, ao analisar as novas configurações religiosas, em especial os trânsitos e as novas dinâmicas que as caracterizam, mostra que

a ênfase moderna na subjetividade, as demandas particulares dos sujeitos religiosos e a incapacidade de resposta das instituições religiosas a tais demandas, produzem essa intensa movimentação no campo religioso. Ampliam-se as alternativas religiosas, aumenta a circulação de crenças, de ideias e práticas religiosas, produzem-se arranjos simbólicos provisórios e híbridos, dispensa-se a mediação do acesso ao sagrado, relaxam-se os vínculos institucionais, a pertença é negociada, e as escolhas não são definitivas. A oferta religiosa é amplificada pelos meios de comunicação, tornando-se mais ou menos atraente de acordo com a procura e as estratégias utilizadas. As fronteiras institucionais já não detêm o crente, que busca, antes de tudo, satisfazer suas próprias demandas, transitando por diferentes grupos ou crenças religiosas, construindo sua trajetória e produzindo novas formas de crer. (SOUZA, 2020, p. 283)

Assim, para além do debate pendular entre secularização versus reencantamento - que parece não estar sendo capaz de captar a complexidade de tais fenômenos -, se exibe a importância de reconhecermos um "caminho do meio", uma terceira via como espaço hermenêutico para compreensão destes fenômenos. Nas palavras de Marcelo Camurça (2008, p. 106): “faz-se mister complexificar tanto a rigidez do paradigma que opõe a secularização 
e a modernidade (vitoriosas) ao sagrado e à religião (exilados) quanto o seu equivalente inverso: o 'retorno do sagrado' e o 'reencantamento' do mundo triunfantes sobre a secularização".

Como temos sinalizado, as novas expressões religiosas sugerem espaços híbridos onde o sagrado convive com o secular de maneira criativa por intermédio de constantes negociações e recombinações, e vice e versa. Desse modo, então, seria no entre - o sagrado e o secular - que as ciências da religião deveriam focar suas atenções.

Essa perspectiva, por suposto, exige uma compreensão transdisciplinar. A formulação do princípio pluralista bebeu das fontes desse caminho.

A transdisciplinaridade engendra, pois, uma atitude trans-cultural e transreligiosa. A atitude trans-cultural designa a abertura de todas as culturas para aquilo que as atravessa e ultrapassa, indicando que nenhuma cultura se constitui em um lugar privilegiado a partir do qual podemos julgar universalmente as outras culturas, como nenhuma religião pode ser a única verdadeira e universal. (ARAGÃO, 2008, p. 142-143)

As mudanças que estamos identificando revelam que as fronteiras entre o religioso e as outras instâncias sociais foram ultrapassadas e que há cada vez menos elementos distintivos entre aquilo que é religioso e o que não é. Tal fato dificulta ainda mais as análises e a compreensão dos complexos fenômenos religiosos contemporâneos. Afinal, mesmo com toda abundância de teorias, ainda nos faltam critérios avaliativos mais apropriados e capazes de nos fazer responder perguntas cruciais, tais como: "o que ainda deve ser considerado religião? O que significa ainda esse religare em cada contexto? Esfumaçou-se a distância entre sagrado e profano?” (MOREIRA, 2008, p. 32). Ao que tudo indica, o desafio de responder adequadamente a tais questões permanece, e a elaboração de boas teorias da religião continua na agenda no século 21. Da mesma forma, são urgentes as socializações das implicações percebidas no tocante às novas configurações religiosas com os setores da sociedade, incluindo as mídias, e como elas interferem nos processos de diversificação do exercício do poder e da autoridade religiosa. O princípio pluralista, especialmente por priorizar as análises que valorizam os entrelugares e fronteiras culturais, procura ser um caminho iluminador desse processo. 


\subsection{Os processos de reconfiguração do quadro religioso}

Tendo em vista o desafio acima referido, seguimos a noção de que a cultura se transforma em religião, como, por exemplo, nas experiências de meditações e autorreflexão como forma religiosa, e a religião se transforma em cultura, como, por exemplo, o lazer, o entretenimento e a prática econômica realizados a partir de formas religiosas.

Não se trata de entender religião e cultura como expressões e esferas distintas; elas estão entrecruzadas, o que gera diversidade e complexidade. Tanto a cultura, como sistema simbólico, fornece relatos do mundo e um conjunto de regras para nele atuar, quanto a religião, por seu curso, faz o mesmo, e, talvez, pelas circunstâncias históricas, de forma ainda mais eficiente e totalizante.

No entanto, conforme nos mostra Alberto Moreira, uma tendência em certo sentido duradoura é um deslocamento do religioso, que transborda os ambientes tidos como tradicionalmente religiosos alcançando outras esferas sociais, como a mídia, o esporte, o cinema, literatura etc. De acordo com esse autor, "estas instituições produzem símbolos, sentidos, crenças, explicações sobre o real e figuras para a imitação, a fidelidade e mesmo a devoção das pessoas" (MOREIRA, 2008, p. 30).

Nesse sentido, diríamos que a religião não está mais apenas contida nos espaços tradicionalmente conhecidos como sagrados, mas vem transbordando para fora deles, atingindo, como já destacado, outras esferas sociais. Olhar as experiências religiosas a partir das fronteiras e dos entrelugares das culturas tem sido a tarefa prioritária do princípio pluralista (RIBEIRO, 2020b).

Um dos elementos da atualidade se caracteriza por espaços interstícios, vazios, que as religiões estabelecidas abandonaram ou não estiveram aptas a responder e que as ciências não se ocuparam. Tais fronteiras ou cruzamentos são os lugares das incertezas, dos imponderáveis da vida, dos mistérios e do acaso, dos fracassos e da morte. Como exemplo, poderíamos compreender diversas experiências religiosas populares como um fenômeno de protesto tanto contra a ineficácia do sistema de saúde pública quanto contra a secularização dos cristianismos dominantes que deixaram um vazio em matéria de resolução dos problemas de saúde. Esse vácuo será, então, ocupado por propostas religiosas alternativas, que exacerbam a linguagem do desejo (STEIL, 2008).

É fato que há a tendência ambígua da perda de força do que se chamou 'grandes instituições religiosas', vivida simultaneamente em meio ao 
fortalecimento dos movimentos religiosos. Para isso, há de se compreender o sentido da antiga e conhecida tensão entre instituição e movimento. A instituição religiosa é uma forma de organização em que há um conjunto de regras e regulamentos que levam determinado grupo a construir uma identidade por meio de segmento hierárquico e de um corpo doutrinal que o caracteriza diante de outros. Já o movimento religioso tem como característica a presença carismática de líderes, com estruturas dinâmicas e flexíveis diante dos regulamentos estabelecidos.

$\mathrm{Na}$ atualidade, as instituições religiosas tradicionais perdem espaço. Isso acontece em razão da não mobilidade delas ante a dinâmica da busca intensa de respostas imediatas para as pessoas e da excessiva preocupação com a manutenção de sua pretensa identidade ou ainda de um rigor moral apregoado como mantenedor da ordem social. Por conseguinte, a sociedade se torna cada vez mais heterogênea e já não comporta mais uma via única de regras baseada em argumentos muitas vezes considerados obsoletos. Sandra Duarte de Souza (2020, p. 285) mostra que

O sujeito religioso contemporâneo escapa às rígidas demarcações das fronteiras religiosas. Sua forma de conhecer e experimentar a religião não cabe nos limites institucionais. Ele ou ela circula física ou virtualmente por diferentes grupos religiosos, acessa saberes, crenças e ritos variados, dispensa a mediação institucional da fé, adiciona e subtrai conhecimentos numa construção singular de seu sistema de sentido, que por vezes combina cosmovisões improváveis do ponto de vista das instituições religiosas. Essa desinstitucionalização da experiência religiosa enfraquece as instituições tradicionais produtoras de sentido. A imprecisão das fronteiras, isto é, a zona borrada entre uma instituição e outra, é o (des)território pelo qual circulam, produtiva e criativamente, indivíduos e ideias.

Entretanto, os movimentos religiosos que, via de regra, não têm o peso de um engessamento institucional ganham pela praticidade e pela não necessária preservação de uma identidade institucional, embora em boa parte dos casos sejam regidos por uma lógica rígida de valores morais e reproduzam contradições das instituições religiosas clássicas. Cecília Mariz (2013, p. 301) ressalta que "a crescente globalização, o questionamento das tradições culturais e também a valorização da autonomia individual são fenômenos inter-relacionados que têm sido identificados como explicação para essa multiplicação de movimentos religiosos e enfraquecimento das instituições 
religiosas". As implicações desses aspectos para o exercício da autoridade religiosa são intensas e diretas.

Esse quadro está ligado também ao primado da experiência, sobretudo sensorial, no campo religioso atual. A realidade hoje reconstrói o valor da experiência, fruto do pensamento moderno iluminista. A saber, na atualidade as formas de espiritualidade são cada vez menos orientadas por uma adesão formal a um conjunto de verdades estabelecidas por uma autoridade eclesiástica, passando a se pautar em um tipo de subjetividade influenciada pela cultura das mídias, na qual importam mais as sensações do que os valores e a memória histórica (STEIL, 2008).

Com isso, o viés comunitário dá lugar à ênfase na experiência individual e de caráter intimista e privado, não obstante manter-se articulado com a dimensão pública possibilitada por projetos políticos institucionais como é bastante comum no contexto das igrejas cristãs no Brasil, por exemplo. Marcelo Camurça (2013, p. 298) indicara que o exame da dimensão organizativa do fenômeno religioso deve levar em conta

as teorias e tipologias como carisma versus instituição, experiência religiosa e suas expressões, igreja versus seita, sistema e campo religioso, sacerdoteprofeta-mago etc., que fornecem conteúdos mais complexos que revestem e dão inteligibilidade histórica, antropológica e sociológica à forma genérica de organização religiosa.

Os diferentes graus que caracterizam a diversidade religiosa brasileira incidem diretamente na variedade de perfis de autoridade religiosa, o que possibilita um considerável leque de formas de atuação e de presença na sociedade.

A diversificação da visão sobre autoridade religiosa no contexto pluralista da sociedade e os vários aspectos socioculturais que reforçam a diversidade e a complexidade das experiências religiosas precisam ser sempre pautados nos debates sobre a temática em questão.

O exercício de autoridade religiosa já era diversificado em função das diferentes fontes que conferem legitimidade a ela, como veremos a seguir. O crescente quadro de pluralismo religioso forma, portanto, um duplo movimento de diversificação.

\section{Fontes de autoridade religiosa}

São muitos os elementos que conferem autoridade às pessoas que pertencem a grupos religiosos e que, baseados nela, passam a exercer 
liderança, representação e respondem com legitimidade pelos grupos a que estão vinculados. Pode-se destacar, ao menos, quatro deles: (i) o conhecimento formal ou informal do texto sagrado (no caso das religiões que o possuem); (ii) um tipo de sapiência, fruto do acúmulo de experiências de vida; (iii) o carisma que determinadas pessoas ou grupos cultivam e que reforça a capacidade de articulação e mobilização coletiva ou a gerência da vida comunitária ou institucional; e (iv) o status socioeconômico e cultural conferido pelas próprias comunidades ou instituições religiosas ou também por setores externos a elas.

$\mathrm{Na}$ atualidade, esses elementos estão cada vez mais interligados, e tem sido bastante comum identificar pessoas que exercem a autoridade religiosa baseada em um ou mais desses aspectos.

\subsection{Conhecimento dos textos sagrados}

No que diz respeito ao conhecimento do texto sagrado (ou no plural para as religiões que possuem mais de um), há que se destacar que ele pode se dar de maneira formal ou informal. Ambas conferem autoridade às pessoas que a ele têm acesso e o dominam.

No tocante ao conhecimento formal do texto sagrado, as instituições religiosas têm estruturas de formação e de verificação da assimilação do conhecimento. Assim, se recorre às faculdades de Teologia e aos seminários cristãos, de nível universitário ou médio, para a formação de padres, pastores e pastoras, às escolas rabínicas, às universidades islâmicas para formação em Ciências Islâmicas com especificações no conhecimento, como Tafsir do Alcorão (especialista em explicação dos seus significados) (BARBOSA, 2020), e a outros espaços institucionais similares. Estes oferecem, com maior ou menor rigor acadêmico, um padrão formal que, em geral, possibilita que as pessoas que os ocupam exerçam cargos e recebam títulos religiosos, respeitadas as regras internas de cada grupo religioso.

Ao conhecimento do texto sagrado somam-se o domínio sobre as doutrinas e o desenvolvimento histórico e institucional delas. Assim, são formados os rabinos e as rabinas, os padres, os pastores e as pastoras, os sheikhs e as sheikhas do Islã, que passam a exercer autoridade religiosa em diferentes níveis. A ideia de conhecimento dos textos sagrados também é fundamental no espiritismo, visto que os livros da 'codificação' kardecista são fundamentais para que o sujeito se forme como espírita e também como médium. A doutrina espírita, como herança da visão positivista, valoriza o 
letramento na busca de comunicações mais aprimoradas e na manutenção da autoridade religiosa (FONSECA, 2020). Embora de forma seletiva, sobretudo por priorizar a visibilidade de líderes católicos (como o papa, arcebispos, bispos e padres), é esse elemento que as mídias convencionais costumam priorizar em suas abordagens.

Há outro tipo de conhecimento do texto sagrado que é adquirido pela leitura ou pela escuta, sem mediações escolares ou acadêmicas. Até a década de 1980, isso foi um fator de forte caracterização das igrejas e grupos pentecostais. Os pastores, com base nos ensinamentos desde a infância ou juventude vindos da própria comunidade, passavam a ser escolhidos e consagrados tendo como base o conhecimento da Bíblia. O mesmo pode ocorrer com pessoas leigas, ou seja, não somente com pastores. Esse conhecimento era associado a outros fatores de empoderamento, como o exemplo pessoal público quanto à ética religiosa e à fidelidade aos costumes da comunidade. A soma desses elementos conferia (e, em certo sentido, ainda confere hoje) maior ou menor poder no exercício da autoridade religiosa. As mídias convencionais, provavelmente por não abrirem espaços para vozes subalternas, reproduzem concepções elitistas e não consideram devidamente o exercício de autoridade religiosa por parte de uma parcela significativa de líderes de diferentes expressões religiosas do campo popular.

\subsection{Sapiência com base em experiências de vida}

Outro elemento que confere autoridade é o que denominamos sapiência. Trata-se da capacidade de oferecer, por meio de exemplos pessoais e do conhecimento dos ritos, mitos e símbolos de suas tradições, indicações práticas às comunidades e grupos no que se refere ao enfrentamento dos principais dilemas da vida.

De alguma forma, ele está ligado ao último aspecto acima descrito, especialmente à ideia de que a capacidade de se articular a trajetória pessoal com os valores e práticas comuns de uma comunidade ou instituição possibilita reconhecimento e adesão por parte dos/as fiéis.

A sapiência, como expressão de conhecimento experiencial, vivido e assimilado com base em laços de convivência e trocas mútuas e acumulativas, se dá mais incisivamente nas formas religiosas menos institucionalizadas ou fora do padrão hegemônico formal do cristianismo.

Essa dimensão está bastante presente nas expressões religiosas e espiritualidades do universo afro-brasileiro. Pais e mães de santo, líderes 
de federações ou articulações de terreiros, são legitimados, em geral, pelo reconhecimento da comunidade daquilo que foi acumulado nas experiências de vida e no conhecimento das raízes de suas tradições, boa parte delas preservada pela oralidade. Isso é feito geralmente com base em indicações práticas para as comunidades e grupos no que diz respeito às demandas do cotidiano. Esse reconhecimento oferece credibilidade às pessoas que o possuem e confere a elas bases para o exercício da liderança e da representatividade. Em função da natureza desse tipo de conhecimento, há maior valorização dos idosos e idosas. Para uma compreensão mais apurada sobre autoridade no universo afro-brasileiro, por exemplo, são necessárias reflexões acerca da ancestralidade, da sabedoria e transmissão oral, do conhecimento da tradição vindo dos antepassados - dos pais e mães de santo antigos, que se expressam na genealogia de uma casa de santo (CARNEIRO, 2020).

Outras expressões religiosas do campo popular, como grupos pentecostais, por exemplo, também vivenciam as tensões entre sapiência e conhecimento formal. Em geral, a noção e as formas de sabedoria advindas da experiência cotidiana e das trajetórias de vida possuem raízes rurais e se mantêm, ainda que fragmentariamente, nas realidades urbanas, por intermédio das expressões orais e espontâneas nos momentos de culto ('testemunhos'), nos exemplos práticos no campo comportamental e familiar e no ensinamento forjados nos espaços coletivos.

As mídias convencionais conferem pouco ou nenhum valor às expressões de autoridade que brotam ou são reforçadas pelo elemento sapiencial.

\subsection{Carisma e poder}

O terceiro elemento que, de acordo com circunstâncias e contextos específicos, pode estar conjugado com os dois primeiros, é o que denominamos carisma. Nos estudos sociológicos, há densa produção a respeito, sobretudo nos estudos weberianos, que realçam a noção do carisma como fator mobilizador que legitima a atuação crítico-profética e de questionamento às tradições efetuadas por líderes de movimentos emergentes. "O carisma, quando emerge, tem um caráter volátil e impermanente, e gera forças transformadoras que dá coragem aos indivíduos para romper com suas rotinas, abrir mão do sentido que sempre norteou suas vidas, correr o risco da anomia, para buscar o novo desconhecido" (MARIZ, 2013, p. 304).

Associada também ao carisma está a capacidade pessoal ou coletiva de gerar admiração, respeito, atração ou até mesmo fascínio, despertando 
simpatia das pessoas e grupos com os quais se convive. No campo religioso, tal capacidade é geralmente compreendida como resultante de uma expressão divina ou sobrenatural, embora também possa ser vista como dom natural marcado fortemente por uma ambientação de espiritualidade.

Os carismas são reconhecidos por diferentes práticas. Uma das mais comuns nos meios religiosos, mas também nos ambientes políticos e educacionais, é a da oratória. A forma e os conteúdos de homilias, pregações, estudos doutrinários, orações e rezas, se bem articulados e fundamentados, geram credibilidade, aceitação e autoridade. Tais condutas em geral reforçam a capacidade de articulação e de mobilização de grupos e incidem positivamente na gerência da vida comunitária ou institucional.

Outro aspecto na diversidade dos carismas e que legitima a aceitação da autoridade religiosa é a intervenção positiva nos processos de cura física e emocional presentes no campo da saúde. Ela se expressa na quase totalidade das religiões e espiritualidades, em maior ou menor grau, dependendo dos níveis de racionalidade que sustentam as propostas religiosas. É bastante comum no campo cristão pentecostal, nos movimentos católicos de renovação carismática, nos centros de Jorey da religião messiânica, nas práticas xamânicas de grupos indígenas, nas espiritualidades dos candomblés, umbandas e encantarias, nas experiências do Santo Daime, nas cirurgias espirituais, expressões de mediunidade e psicografia no campo espírita, entre tantos outros. As mídias convencionais costumam apresentar tais exercícios de autoridade religiosa como expressão exótica e excêntrica.

\subsection{Status socioeconômico e cultural}

O quarto elemento que confere autoridade no contexto dos grupos religiosos e que é articulado sobretudo com o primeiro (o conhecimento formal dos textos sagrados) é a valorização, por parte das comunidades e instituições e de setores externos a elas, do status socioeconômico e cultural que uma pessoa ou grupo possuem. Quanto mais elevado for, mais facilidades para o exercício da autoridade terão.

Embora de natureza sociológica, esse elemento é articulado no contexto das experiências religiosas a partir de justificativas de certo teor ideológico e de práticas excludentes, visíveis ou subliminares. Ele não é efetivado sem a consideração dos argumentos de natureza religiosa e das expressões culturais que, no caso brasileiro, são historicamente marcadas pelo coronelismo, pelo elitismo e pela supremacia política e cultural das classes sociais altas e médias. 
Esse elemento é fortemente desafiador para as religiões populares, especialmente as afro-indígenas e pentecostais, e em todas elas há reprodução em variados níveis dessa concepção. Em áreas periféricas, são comuns os exemplos de pessoas ou famílias que, por possuírem automóvel ou moradia em melhores condições do que as demais, encontram caminhos mais acessíveis ao exercício da autoridade religiosa. É importante reconhecer que isso não se dá sem o domínio dos aspectos específicos das tradições religiosas que integram e que possuem força significativa nos processos de poder, gestão e liderança.

O status socioeconômico e cultural se revela em diferentes níveis, especialmente no acesso aos espaços acadêmicos, às esferas do poder público e à ocupação das mídias. Isso explica a importância dele para a nossa análise no tocante ao tema da autoridade no campo religioso.

Em todos os referidos elementos, em seus diferentes níveis, há outros exemplos que podem ser extraídos da variedade de expressões religiosas que compõe o quadro brasileiro. Todos são desafiadores, tanto para as análises científicas da religião quanto para o exercício prático no campo da comunicação.

Para o aprofundamento deles, recorrer ao princípio pluralista tem sido uma indicação salutar. Isso porque tal princípio possibilita divergências e convergências novas, outros pontos de vistas, perspectivas críticas e autocríticas para diálogo, empoderamento de grupos e de visões subalternas e formas de alteridade e de inclusão, considerados e explicitados os diferenciais de poder presentes na sociedade (RIBEIRO, 2020).

\section{O papel das mídias e a autoridade religiosa}

As mídias, no início do século 21, constituíram palco de mudanças significativas para as religiões. Brenda Carranza (2013, p. 540) mostra que "de tal forma isso ocorreu que, de coadjuvante, os mass media passaram a ser protagonistas; de meros instrumentos, assumiram a pauta de questões religiosas relevantes, as quais ainda se constituem como objeto de conflitos".

Esses processos estão conectados com as dimensões do poder político e econômico, em suas mais diversas interações e ambiguidades. O acesso às mídias, assim como as interações midiáticas, seja em espaços tradicionais como o rádio e a TV, seja as digitais em franco crescimento associado à produção cultural e de entretenimento, conferem visibilidade aos grupos religiosos no espaço público, com consequências diretas para o exercício da autoridade. 
Magali Cunha (2020, p. 131) ressalta que a transmissão eletrônica de celebrações e rituais de diversas religiões, desde as missas católicas e cultos evangélicos até as cerimônias de matriz afro, estabeleceu um novo caráter de produção e de liderança dessas práticas. "Igualmente, o aconselhamento e a orientação religiosos ganharam novos contornos com as possibilidades que as mídias digitais abriram por meio do atendimento a distância". A autora mostra que

As mídias não apenas publicizam e difundem religião, mas também modelam as religiões e as religiosidades de diferentes formas, especialmente por conta da tecnicidade que gera as novas ritualidades e novas formas de partilha comunitária da fé. Os meios de comunicação assumiram, em alguns aspectos, muitas funções sociais historicamente oferecidas pelas religiões: contribuem para a articulação e manutenção de comunidades sociais, tornaram-se fundamentais para a celebração pública de grandes eventos, ritualizam mudanças sociais, proporcionam orientação moral e promovem diversas formas de adoração por meio da cultura das celebridades e seus fãs. E ainda, as mídias digitais criaram novas possibilidades para que os fiéis se engajem em comunicação e práticas religiosas fora do campo de controle das religiões. (CUNHA, 2020, p. 131)

Em relação ao exercício da autoridade religiosa, ao poder e à influência das mídias, há outras situações que poderiam ser ilustrativas das mudanças que ocorrem na sociedade. No campo cristão, por exemplo, um pastor evangélico ou um padre católico que possui certo destaque nas mídias pode exercer maior autoridade em determinada comunidade do que o pastor ou padre da qual é líder. Situações similares ocorrem em outros grupos religiosos.

Nesse aspecto, a noção de autoridade torna-se relativizada pela atuação dos líderes religiosos nas mídias, como artistas, blogueiros, youtubers, vários deles transformados em celebridades. Lideranças religiosas locais passam a não ter mais o controle do sagrado e da doutrina como em períodos anteriores (HOOVER, 2014).

\section{Considerações finais}

O objetivo de nossa análise foi apresentar um leque de questões em torno do debate sobre autoridade religiosa, com destaque aos fatores que conferem distinções e diferenciações na forma em que ela pode ser vista no contexto plural das sociedades na atualidade. 
Os resultados pretendem fazer indicações para os estudos de religião no que diz respeito a compreensões mais apuradas sobre a diversidade religiosa. Como o estudo se originou na interlocução com um grupo de pesquisa na área de religião e comunicação, esperamos que as reflexões apresentadas cooperem com a tarefa de oferecer elementos sobre o pluralismo religioso aos profissionais desse campo, especialmente no trato de questões que envolvem temas relacionados à autoridade religiosa.

Como tem sido priorizado em nossos estudos, as avaliações foram feitas à luz do princípio pluralista. Nesse sentido, os olhares sobre as experiências religiosas priorizaram interpretá-las a partir dos entrelugares e fronteiras das culturas, dos espaços interstícios e não institucionais de poder e das possibilidades de visibilidade e empoderamento dos grupos subalternos. Com isso, foi possível realçar as formas pelas quais o poder é exercido internamente nos distintos contextos religiosos, considerando as diversas contradições e ambiguidades que eles possuem.

Foram dados quatro passos para a abordagem dos principais conteúdos do tema. O primeiro, uma síntese do princípio pluralista, em especial suas bases conceituais relacionadas às já referidas noções de entrelugares e fronteiras das culturas, as tensões criativas da sociologia das ausências e das emergências, o valor da alteridade ecumênica e o caráter crítico e propositivo dos estudos decoloniais, principalmente os questionamentos às formas de poder, de saber e de ser.

O segundo bloco apresentou dados sobre o quadro do pluralismo religioso brasileiro. Entre os pontos indicados, estão a visão diversificada acerca de autoridade religiosa, considerando-se o contexto plural da sociedade, e a diversidade, a complexidade e os movimentos socioculturais internos das expressões religiosas. Nesse quadro, se destacam variados processos de reconfiguração do quadro religioso brasileiro como o deslocamento do religioso para esferas culturais, o primado das experiências sensoriais no campo religioso, as variações que a diversidade sexual e de gênero trazem ao campo de cada expressão religiosa e as formas de fundamentalismos, ecumenismos, trânsitos e múltiplas participações religiosas.

O terceiro bloco abordou mais especificamente a temática da autoridade religiosa e das fontes que conferem legitimidade a ela, possibilitando o exercício da liderança e da representação. A pesquisa destacou o conhecimento formal ou informal do texto sagrado (no caso das religiões que o possuem); as formas de sapiência acumuladas no conjunto das experiências 
de vida; o carisma que determinadas pessoas ou grupos cultivam e que reforça a capacidade de articulação e mobilização coletiva ou na gestão da vida comunitária ou institucional; e o status socioeconômico e cultural conferido pelas próprias comunidades ou instituições religiosas ou ainda por setores externos a elas.

Por fim, a relação entre o papel das novas formas de comunicação eletrônica e o exercício da autoridade religiosa. As mídias, no início do século 21, se constituíram em palco e veículo de grandes mudanças para as religiões. Elas passaram de coadjuvantes a protagonistas de processos religiosos, com variadas implicações no tocante aos aspectos de autoridade. Como visto, os processos midiáticos possuem íntima relação com o poder político e econômico. Nesse sentido, o acesso e a participação neles, assim como o recurso aos espaços e aos bens da produção cultural e de entretenimento, conferem visibilidade para os grupos religiosos no espaço público. O exercício da autoridade religiosa está diretamente implicado nesse contexto.

\section{Referências}

ARAGÃO, Gilbraz. Do transdisciplinar ao transreligioso (p. 133-148). In: TEPEDINO, Ana Maria; ROCHA, Alessandro. A teia do conhecimento: fé, ciência e transdisciplinaridade. São Paulo: Paulinas, 2008.

ARAGÃO, Gilbraz. Transreligiosidade (p. 288-295). In: RIBEIRO, Claudio de Oliveira; ARAGÃO, Gilbráz; PANASIEWICZ, Roberlei. Dicionário do pluralismo religioso. São Paulo: Recriar, 2020.

BARBOSA, Francirosy Campos. Identidades em construção e diálogo inter-religioso (p. 99-105). In: RIBEIRO, Claudio de Oliveira; ARAGÃO, Gilbráz; PANASIEWICZ, Roberlei.

Dicionário do pluralismo religioso. São Paulo: Recriar, 2020.

BHABHA, Homi. O local da cultura. Belo Horizonte: Editora UFMG, 2001.

CAMURÇA, Marcelo Ayres. Religião como organização (p. 287-299). In: PASSOS, João Décio; USARSKI, Frank (org.). Compêndio de Ciência da Religião. São Paulo: Paulinas/ Paulus, 2013.

CAMURÇA, Marcelo Ayres. Ciências Sociais e Ciências da Religião. São Paulo: Paulinas, 2008. CARNEIRO, Jorge Érica. Pluralidade religiosa afro-brasileira (p. 181-186). In: RIBEIRO, Claudio de Oliveira; ARAGÃO, Gilbráz; PANASIEWICZ, Roberlei. Dicionário do pluralismo religioso. São Paulo: Recriar, 2020.

CARRANZA, Brenda. Linguagem midiática e religião (p. 539-555). In: PASSOS, João Décio; USARSKI, Frank (org.). Compêndio de Ciência da Religião. São Paulo: Paulinas/Paulus, 2013.

CUNHA, Magali do Nascimento. Midiatização das religiões (p. 129-133). In: RIBEIRO, Claudio de Oliveira; ARAGÃO, Gilbráz; PANASIEWICZ, Roberlei. Dicionário do pluralismo religioso. São Paulo: Recriar, 2020. 
FONSECA, Grazyelle. Espíritas no Brasil (p. 64-71). In: RIBEIRO, Claudio de Oliveira; ARAGÃO, Gilbráz; PANASIEWICZ, Roberlei. Dicionário do pluralismo religioso. São Paulo: Recriar, 2020.

FRANCO, Clarisse de. Pluralidade religiosa no mundo (p. 194-201). In: RIBEIRO, Claudio de Oliveira; ARAGÃO, Gilbráz; PANASIEWICZ, Roberlei. Dicionário do pluralismo religioso. São Paulo: Recriar, 2020.

FRANCO, Clarisse de; RIBEIRO, Claudio de Oliveira. A pluralidade religiosa global e nacional em questão. Caminhos, Goiânia, PUC Goiás, v. 18, n. 2, p. 308-324, 2020.

HOOVER, Stewart. Mídia e religião: premissas e implicações para os campos acadêmico e midiático. Comunicação e Sociedade, São Bernardo do Campo, Umesp, v. 35, n. 2, p. 41 68, 2014.

MARIZ, Cecília Loreto. Instituições tradicionais e movimentos emergentes (p. 301-312). In: PASSOS, João Décio; USARSKI, Frank (org.). Compêndio de Ciência da Religião. São Paulo: Paulinas/Paulus, 2013.

MIGNOLO, Walter. Desobediência epistêmica: a opção descolonial e o significado de identidade em política. Cadernos de Letras da UFF - Dossiê: literatura, língua e identidade, Niterói, n. 34, p. 287-324, 2008.

MOREIRA, Alberto da Silva. O futuro da religião no mundo globalizado (p. 17-35). In: MOREIRA, Alberto da Silva; DIAS DE OLIVEIRA, Irene (org.). O futuro da religião na sociedade global. São Paulo: Paulinas/UCG, 2008.

RIBEIRO, Claudio de Oliveira; CATENACI, Giovanni. O pluralismo religioso em debate. São Paulo: Reflexão, 2017.

RIBEIRO, Claudio de Oliveira. O princípio pluralista. São Paulo: Loyola, 2020.

RIBEIRO, Claudio de Oliveira. Religião, decolonialidade e o princípio pluralista. Numen, Juiz de Fora, UFJF, v. 23, n. 1, p. 21-40, 2020b.

RIBEIRO, Claudio de Oliveira (org.). Religiões e direitos humanos: múltiplos olhares. Campinas: Saber Criativo, 2021.

SANTOS, Boaventura de Souza. A gramática do tempo: para uma nova cultura política. São Paulo: Cortez, 2010.

SERRA, Cris; LEITE, Vanessa. (Des) construindo tradições: diversidade sexual e de gênero em disputas de narrativas e de valores religiosos (p. 203-252). In: RIBEIRO, Claudio de Oliveira (org.). Religiões e direitos humanos: múltiplos olhares. Campinas: Saber Criativo, 2021.

SOUZA, Sandra Duarte de. Religião e identidades de gênero (p. 185-196). In: BELLOTTI, Karina Kosicki et al. (org.). Religião e sociedade na América Latina. São Bernardo do Campo: Umesp, 2010.

SOUZA, Sandra Duarte de. Trânsito religioso (p. 282-288). In: RIBEIRO, Claudio de Oliveira; ARAGÃO, Gilbráz; PANASIEWICZ, Roberlei. Dicionário do pluralismo religioso. São Paulo: Recriar, 2020. 
STEIL, Carlos Alberto. Oferta simbólica e mercado religioso na sociedade global (p. 7-16). In: MOREIRA, Alberto da Silva; DIAS DE OLIVEIRA, Irene (org.). O futuro da religião na sociedade global. São Paulo: Paulinas/UCG, 2008.

TEIXEIRA, Faustino. O fundamentalismo em tempos de pluralismo religioso (p. 69-80). In: MOREIRA, Alberto da Silva; DIAS DE OLIVEIRA, Irene (org.). O futuro da religião na sociedade global. São Paulo: Paulinas/UCG, 2008.

TEIXEIRA, Faustino; MENEZES, Renata (org.). Religiões em movimento: o censo de 2010. Petrópolis: Vozes, 2013.

TOSTES, Angélica. Múltipla pertença religiosa (p. 156-161). In: RIBEIRO, Claudio de Oliveira; ARAGÃO, Gilbráz; PANASIEWICZ, Roberlei. Dicionário do pluralismo religioso. São Paulo: Recriar, 2020.

Submetido em: 15-6-2021

Aceito em: 27-1-2022 